\title{
COMPACTAÇÃO DE UM LATOSSOLO SUBMETIDO AO TRÁFEGO DE SKIDDER COM DIFERENTES RODADOS
}

\author{
Eduardo da Silva Lopes ${ }^{1}$, Jean Alberto Sampietro ${ }^{2}$, André Leonardo Nasser Pereira ${ }^{2}$, Diego de Oliveira ${ }^{3}$ \\ ${ }^{1}$ Eng. Florestal, Dr., Depto. de Engenharia Florestal, UNICENTRO, Irati, PR, Brasil - eslopes@pq.cnpq.br \\ ${ }^{2}$ Eng. Florestal, Mestrando em Ciências Florestais, UNICENTRO, Irati, PR, Brasil - ngsampietro@ yahoo.com; \\ nasserandre@hotmail.com \\ ${ }^{3}$ Acadêmico de Engenharia Florestal, UNICENTRO, Irati, PR, Brasil - diegotst2007@ yahoo.com.br
}

Recebido para publicação: 09/08/2010 - Aceito para publicação: 02/12/2010

\begin{abstract}
Resumo
O processo de mecanização da colheita de madeira possibilitou um aumento significativo na produtividade e na qualidade das operações. Entretanto, o tráfego intenso de máquinas pesadas tem sido o grande responsável pela compactação do solo em áreas florestais. Este trabalho teve como principal objetivo avaliar os níveis de compactação de um Latossolo causada pelo trator florestal skidder com rodados de pneus e rodados de pneus recobertos com semiesteiras. O estudo foi conduzido nas áreas de colheita de madeira de uma empresa florestal localizada no estado do Paraná. A compactação do solo foi determinada por meio de alterações nas variáveis de densidade, porosidade total, porosidade de aeração e resistência do solo à penetração. As amostras de solo e os dados de resistência à penetração foram coletados em quatro pontos igualmente espaçados ao longo das trilhas de tráfego das máquinas e em linhas sem tráfego (testemunha), em três níveis de profundidade $(0$ a 15,15 a 30 e 30 a $50 \mathrm{~cm})$. A análise dos resultados mostrou que o skidder equipado com rodados de pneus foi responsável pela maior alteração na densidade do solo, com 1,22 e $1,17 \mathrm{mg} \cdot \mathrm{m}^{-3}$ nas profundidade de 0 a 15 e 15 a $30 \mathrm{~cm}$, respectivamente. Não houve alteração significativa nas propriedades físicas do solo devido ao tráfego do skidder com os diferentes tipos de rodados, mostrando que a instalação da semiesteira nos rodados das máquinas não acarretou em redução da compactação do solo.

Palavras-chave: Compactação; tipos de rodados; extração florestal.
\end{abstract}

\begin{abstract}
Compaction of a latosol subjected to skidder traffic with different wheeled. The process of mechanization of timber harvesting allowed a significant increase in productivity and quality of operations. However, heavy traffic of large machines has been largely responsible for soil compaction in forest areas. This research aimed to evaluate the latosol compaction caused by skidder with tires and tracks over the tires. The study was developed in the logging areas of a forestry company located in Parana State. Soil compaction was evaluated by soil bulk density, aeration porosity, total porosity and penetrometer resistance. The soil samples and date of penetrometer resistance were taken at four points equally spaced along both the trails with and without traffic at three depth levels ( 0 to 15,15 to 30 and 30 to $50 \mathrm{~cm}$ ). The results showed that the skidder equipped with tires was responsible for the greatest change in density, with 1.22 and $1.17 \mathrm{mg} \cdot \mathrm{m}-3$ in the depth of 0 to 15 and 15 to $30 \mathrm{~cm}$, respectively. There was not significant change in soil physical properties caused by skidder traffic with the different wheeled types, proving that the installation of the tracks over tires did not result in smaller soil compaction.
\end{abstract}

Keywords: Compaction; wheeled types; wood extraction.

\section{INTRODUÇÃO}

A colheita e o transporte de madeira são considerados as etapas mais importantes do setor florestal, pois representam a operação final de um ciclo de produção. Além disso, são influenciados por diversos fatores que interferem na execução das operações e são onerosas em termos de custo de produção, podendo representar mais de $50 \%$ do custo final da madeira posta na fábrica (MACHADO, 1994). 
As operações mecanizadas de colheita de madeira iniciaram no país, de forma significativa, a partir da década de 1990, com a abertura do mercado brasileiro à importação. O avanço da mecanização trouxe vários benefícios ao setor florestal, como redução da dependência de mão de obra, melhorias das condições de trabalho, fornecimento regular e em quantidade crescente de madeira, aumento da produtividade e redução dos custos de produção (BRAMUCCI; SEIXAS, 2002). Entretanto, os sistemas mecanizados de colheita de madeira têm causado um processo acelerado de degradação do solo, principalmente devido ao aumento do tráfego de máquinas de grande porte, resultando no desequilíbrio das características físicas, químicas e biológicas do solo e podendo afetar o potencial produtivo dos plantios florestais (DIAS JÚNIOR, 1999).

Na colheita de madeira, é importante destacar a operação de extração, que é considerada a etapa mais complexa e a maior causadora de impactos no meio ambiente. Nessa etapa, são amplamente utilizados os tratores florestais arrastadores skidders, que realizam a extração das árvores do interior do talhão até as margens das estradas ou pátios intermediários, na forma de arraste. Os rodados podem ser de pneus, esteiras ou pneus recobertos com semiesteiras. Souza et al. (2002) citam que os principais problemas relacionados ao arraste da madeira com o trator florestal skidder referem-se à passagem da máquina sobre as pilhas das árvores, à perda de rendimento em função das condições do terreno e aos danos causados ao solo, principalmente em termos de compactação.

A compactação é a ação mecânica por meio da qual se impõe ao solo a redução de seu índice de porosidade, podendo ser definida como a relação entre o volume de espaços vazios e o volume de sólidos (CAMARGO, 1983; SEIXAS, 1988). Trata-se de uma tensão aplicada sobre o solo resultante de mudanças em termos de incremento da densidade, redução do espaço poroso, infiltração e movimento lento da água do solo e maior resistência mecânica ao crescimento das raízes. Já Soane e Ouwerkerk (1994) diz que a compactação do solo é o processo em que ocorre o aumento na densidade aparente, com incremento da resistência à penetração e redução da porosidade total e da permeabilidade.

Existem diversos fatores que influenciam a compactação do solo, podendo-se destacar a textura, o teor de matéria orgânica, o conteúdo de água, o tipo e número de passadas das máquinas, a presença de resíduos da colheita sobre o terreno e os tipos de rodados utilizados nas máquinas (PORTERFIELD; CARPENTER, 1986; WARKOTSCH, 1994).

Seixas (2000), estudando a influência do número de passadas das máquinas sobre o solo, verificou que o efeito do tráfego dos tratores florestais foi maior após as primeiras passadas, sendo que o aumento da densidade do solo nas trilhas de tráfego está relacionado ainda com os tipos de rodados, o teor de matéria orgânica e o tipo de máquina utilizada no sistema de colheita de madeira. Seixas e Souza (2007) verificaram que $80 \%$ do incremento da compactação de um solo ocorreu após as cinco primeiras passadas de um forwarder. Já Eavis (1972) diz que um fator importante que pode influenciar na compactação do solo refere-se ao teor de umidade, tendo grande contribuição na redução e na redistribuição do espaço poroso. Segundo o mesmo autor, solos secos são mais resistentes às mudanças na distribuição do tamanho dos poros, e essa resistência é reduzida com o aumento do conteúdo de água.

Makkonen (1989) afirma que a camada de resíduos florestais presentes sobre o terreno é um importante fator que contribui para a redução do nível de compactação do solo. Seixas et al. (1995) detectaram reduções significativas, em torno de $40 \%$, do incremento na densidade de um solo quando do tráfego de um forwarder sobre uma camada residual da colheita de madeira.

Outro fator importante que pode influenciar na compactação do solo refere-se ao tipo de rodados utilizados nas máquinas florestais. Hassan e Sirois (1985), estudando a compactação do solo, constataram um aumento significativo a partir de $10 \mathrm{~cm}$ de profundidade na densidade, afirmando que a compactação ocorreu devido às cargas aplicadas pelos rodados das máquinas no arraste da madeira.

Já Lima e Sirtoli (2006) dizem que o peso das máquinas é o fator que determina a profundidade da compactação do solo, independentemente da pressão aplicada na sua superfície. A distribuição do peso das máquinas sobre a superfície do solo explica o fato de os tratores com rodados de esteiras compactarem menos o solo em relação aos tratores com rodados de pneus, devido à maior superfície de contato da esteira com o solo. Warkotsch (1994) verificou que, dependendo da relação carga/distribuição nos rodados das máquinas, a compactação do solo pode chegar até $80 \mathrm{~cm}$ de profundidade, ressaltando ainda que a compactação máxima situa-se na profundidade entre 30 e $55 \mathrm{~cm}$.

Segundo Bygdén et al. (2003), os skidders com rodados de esteiras ou pneus recobertos com semiesteiras têm sido amplamente utilizados no arraste de madeira, principalmente em solos úmidos, com 
baixa capacidade de suporte, podendo ainda reduzir a compactação e os distúrbios causado ao solo. Além disso, permitem o acesso das máquinas em áreas declivosas, onde aquelas equipadas com rodados de pneus não são capazes de atuar (LOPES et al., 2007).

Portanto, diante da importância da colheita de madeira e dos inúmeros modelos de máquinas disponíveis no mercado, torna-se necessário a realização de estudos que visem compreender os fatores que explicam o processo de compactação do solo, possibilitando subsidiar a execução das operações da colheita de madeira de forma eficiente e ambientalmente correta.

Este trabalho teve por objetivo avaliar os níveis de compactação causados em um Latossolo submetido ao tráfego do trator florestal skidder equipado com diferentes tipos de rodados.

\section{MATERIAL E MÉTODOS}

\section{Área de estudo}

Este trabalho foi conduzido nas áreas de colheita de madeira pertencente a uma empresa florestal

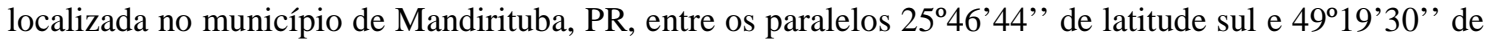
longitude oeste, com uma altitude média de $840 \mathrm{~m}$.

O clima característico da região é o subtropical úmido mesotérmico, ou $\mathrm{Cfb}$ (Köppen), com precipitação média anual de $1.400 \mathrm{~mm}$ e temperatura média anual de $22{ }^{\circ} \mathrm{C}$.

O solo da área de estudo foi classificado como um Latossolo Bruno Distrófico típico (LBd), com relevo suave ondulado e declividade média de 4,5 , textura argilosa com 449,0; 255,0 e 296,0 g.kg ${ }^{-1}$ de argila, silte e areia, respectivamente, umidade gravimétrica de $0,418,0,395$ e $0,381 \mathrm{~kg} \cdot \mathrm{kg}^{-1}$ e teor de carbono orgânico de $12,8,8,8$ e 7,1 dag. $\mathrm{kg}^{-1}$, nas camadas de 0 a 15,15 a 30 e 30 a $50 \mathrm{~cm}$ de profundidade, respectivamente.

Os dados foram coletados durante o período de março a abril de 2009, em plantios de Pinus taeda, no regime de corte raso.

\section{Descrição dos equipamentos}

O experimento foi conduzido utilizando-se um trator florestal skidder, marca Caterpillar, modelo 545 , com tração $4 \times 4$, potência nominal de $225 \mathrm{HP}$, garra com capacidade de carga de $1,5 \mathrm{~m}^{2}$, peso operacional de 18,2 toneladas, equipado com rodados de pneus e com rodados de pneus recobertos com semiesteiras da marca Eco Wheel Track, da Olofsfors (Figura 1).
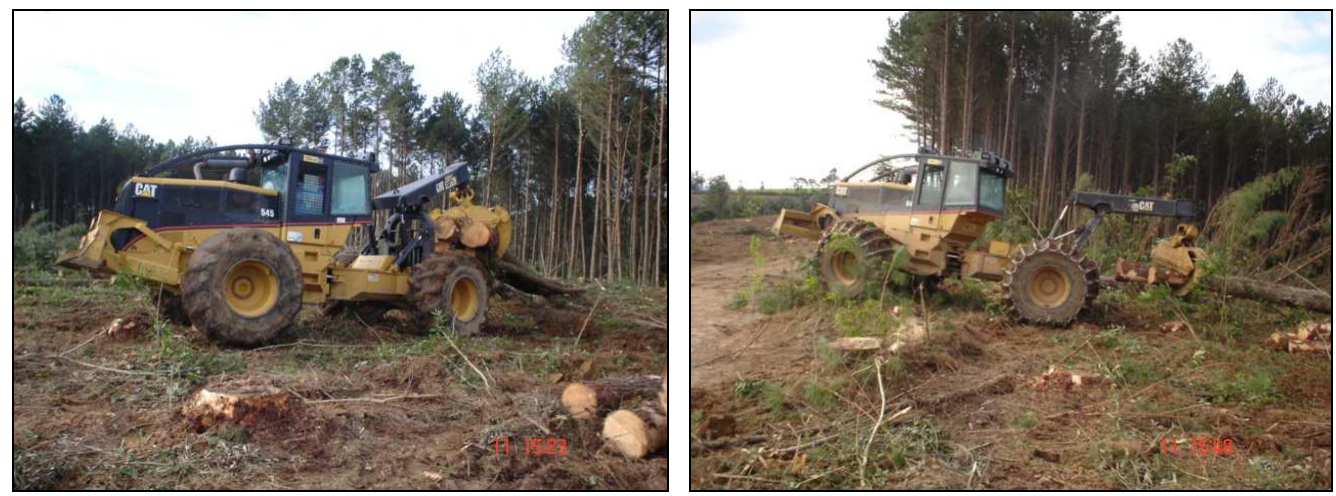

Figura 1. Skidders com rodados de pneus (esquerda) e rodados de pneus recobertos com semiesteiras (direita).

Figure 1. Skidders with wheeled of tires (left) and wheeled of tracks over the tires (right).

\section{Coleta de dados}

A compactação do solo foi determinada pelas variáveis densidade do solo (Ds), porosidade total $(\mathrm{Pt})$, porosidade de aeração $(\mathrm{PA})$ e resistência do solo à penetração $(\mathrm{RP})$. Inicialmente foram estabelecidas no interior do talhão três parcelas amostrais $(6 \times 18 \mathrm{~m})$, com condições semelhantes para o tráfego dos skidders equipados com os dois tipos de rodados. Os tratamentos avaliados foram: SKP (skidder com 
rodados de pneus), SK4 (skidder com os rodados de pneus recobertos com semiesteiras) e TEST (testemunha - linha sem tráfego).

Para a determinação da densidade, foram coletadas amostras de solo com estrutura preservada com anéis volumétricos de $100 \mathrm{~cm}^{3}(5,0 \mathrm{~cm}$ de diâmetro x $5,1 \mathrm{~cm}$ de altura), em quatro pontos equidistantes cinco metros entre si, distribuídos ao longo da trilha de arraste e em três profundidades do perfil do solo: 0 a $15 \mathrm{~cm}, 15$ a $30 \mathrm{~cm}$ e 30 a $50 \mathrm{~cm}$. Após a coleta, as amostras do solo foram pesadas, para obtenção do peso úmido, secas em estufa a $105{ }^{\circ} \mathrm{C}$ durante 24 horas e novamente pesadas para obtenção do peso seco, procedendo-se então à determinação da densidade por meio da seguinte expressão:

em que: Ds $=$ densidade do solo $\left(\mathrm{mg} \cdot \mathrm{m}^{-3}\right)$;

$$
\mathrm{Ds}=\frac{\mathrm{Mss}}{\mathrm{Vs}}
$$

Mss = massa do solo seco em estufa a $105^{\circ} \mathrm{C}(\mathrm{mg})$;

$\mathrm{Vs}=$ volume do anel volumétrico $\left(\mathrm{m}^{3}\right)$.

A porosidade total foi determinada pelo método indireto, seguindo a expressão:

$$
\mathrm{Pt}=\frac{\mathrm{Dp}-\mathrm{Ds}}{\mathrm{Dp}}
$$

em que: $\mathrm{Pt}=$ porosidade total $\left(\mathrm{m}^{3} \cdot \mathrm{m}^{-3}\right)$;

Ds $=$ densidade do solo $\left(\mathrm{mg} \cdot \mathrm{m}^{-3}\right)$;

$\mathrm{Dp}=$ densidade de partículas do solo $\left(\mathrm{mg} \cdot \mathrm{m}^{-3}\right)$.

A porosidade livre de água ou porosidade de aeração, que é a fração do volume de solo ocupado por poros preenchidos por ar, foi determinada pela seguinte expressão:

em que: $\mathrm{PA}=$ porosidade de aeração $\left(\mathrm{m}^{3} \cdot \mathrm{m}^{-3}\right)$;

$$
\mathrm{PA}=\mathrm{Pt}-\mathrm{Uv}
$$

$\mathrm{Pt}=$ porosidade total $\left(\mathrm{m}^{3} \cdot \mathrm{m}^{-3}\right)$;

$\mathrm{Uv}=$ umidade volumétrica do solo $\left(\mathrm{m}^{3} \cdot \mathrm{m}^{-3}\right)$.

A resistência do solo à penetração foi determinada por meio de um penetrógrafo da marca Soil Control, modelo SC-60, com uma haste de $600 \mathrm{~mm}$ de comprimento, 9,53 $\mathrm{mm}$ de diâmetro e cone de $129,3 \mathrm{~mm}^{2}$ de área de base. Os dados de resistência do solo à penetração foram obtidos próximos aos pontos no interior das parcelas onde foram coletadas as amostras do solo. A resistência do solo à penetração foi medida por meio do índice de cone (IC) nos intervalos de 0 a 15,15 a 30 e 30 a $50 \mathrm{~cm}$ para cada tratamento, conforme metodologia da ASAE S 313, citada por Balastreire (1987).

\section{Análise estatística}

O delineamento estatístico utilizado foi o inteiramente casualizado, sendo que os valores das variáveis foram submetidos à análise de variância e as médias comparadas pelo teste de Dunnett ao nível de $5 \%$ de significância. Foram ainda ajustadas equações de regressão para verificar a relação entre a densidade e a resistência do solo à penetração com os tipos de rodado.

\section{RESULTADOS E DISCUSSÃO}

\section{DENSIDADE DO SOLO}

A figura 2 mostra o comportamento da densidade do solo em relação aos diferentes tratamentos estudados. Como pode ser observado, houve um acréscimo na densidade do solo devido ao tráfego do skidder durante o arraste dos feixes de árvores.

Esse resultado ficou mais evidente na situação de tráfego da máquina equipada com rodados de pneus, com 1,22 e $1,17 \mathrm{mg} \cdot \mathrm{m}^{-3}$ nas camadas mais superficiais do solo, ou seja, 0 a 15 e 15 a $30 \mathrm{~cm}$, respectivamente, com diferença estatística em relação à testemunha $\left(1,05\right.$ a $\left.1,01 \mathrm{mg} . \mathrm{m}^{-3}\right)$. Por outro lado, na situação de tráfego da máquina equipada com os rodados recobertos com semiesteiras, houve uma menor alteração na densidade do solo comparada à testemunha, com diferença significativa somente na 
camada de 15 a $30 \mathrm{~cm}$ de profundidade.

É importante ressaltar que em nenhum dos tratamentos estudados houve incremento na densidade do solo acima do limite de 15 a 20\%, que, de acordo com Geist et al. (1989), poderá restringir o crescimento radicular das plantas e afetar o crescimento da floresta (Tabela 1). Entretanto, apesar de não ser atingido tal valor, os resultados sugerem que as pressões aplicadas pelo tráfego das máquinas estão acima da capacidade de suporte do solo.

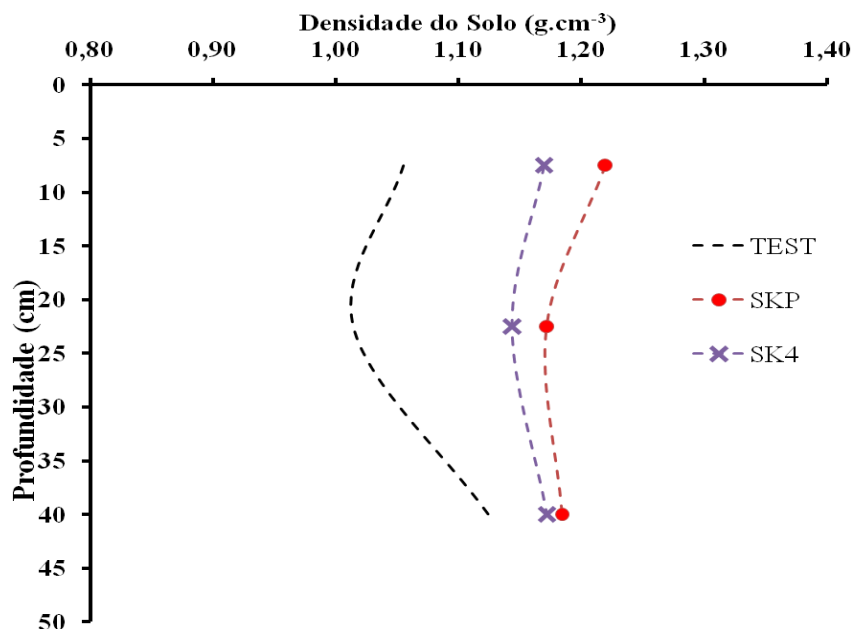

Figura 2. Densidade média do solo nos diferentes tratamentos.

Figure 2. Average of soil bulk density at the different treatments.

Foi possível ainda observar que a densidade do solo na condição sem tráfego (testemunha) na profundidade de 30 a $50 \mathrm{~cm}$ foi maior em relação às demais profundidades estudadas. Tal fato também é relatado por diversos autores, que afirmam que essa situação é uma tendência natural do solo, devido à menor quantidade de matéria orgânica, à menor agregação e ao peso das camadas sobrejacentes.

Tabela 1. Valores médios de densidade do solo $\left(\mathrm{mg} \cdot \mathrm{m}^{-3}\right)$ nos diferentes tratamentos e profundidades.

Table 1. Average values of soil bulk density $\left(\mathrm{mg} \cdot \mathrm{m}^{-3}\right)$ at the different treatments and depths.

\begin{tabular}{lccc}
\hline \multirow{2}{*}{ Tratamento } & \multicolumn{3}{c}{ Profundidade (cm) } \\
\cline { 2 - 4 } & $\mathbf{0 ~ a ~ 1 5}$ & $\mathbf{1 5} \mathbf{a} \mathbf{3 0}$ & $\mathbf{3 0}$ a 50 \\
\hline TEST & 1,05 & 1,01 & 1,12 \\
SKP & $1,22 \neq$ & $1,17 \neq$ & 1,18 \\
SK4 & 1,17 & $1,14 \neq$ & 1,17 \\
Valor $F$ & $4,28^{*}$ & $10,21^{* *}$ & $0,32^{\text {ns }}$ \\
\hline
\end{tabular}

Médias seguidas de ₹ na coluna diferem estatisticamente da testemunha (TEST) pelo teste de Dunnett a $5 \%$ de significância; *: significativo a $5 \%$; **: significativo a $1 \% ;{ }^{\text {ns }}$ : não significativo.

\section{POROSIDADE TOTAL E DE AERAÇÃo}

Os resultados observados na figura 3 e na tabela 2 mostram que as maiores reduções de porosidade ocorreram nas camadas superficiais do solo $(0$ a 15 e 15 a $30 \mathrm{~cm})$, sendo o local onde o sistema radicular das plantas necessita de condições apropriadas para o seu desenvolvimento inicial. Segundo Ballard (2000), a redução do tamanho dos poros leva a uma maior retenção de água no solo e, por conseguinte, maior restrição às trocas gasosas, que decorrem também da diminuição da Pt. Já na camada de 30 a $50 \mathrm{~cm}$ de profundidade, verificou-se um acréscimo dos poros nas situações de tráfego dos skidders com rodados de pneus e com os quatro rodados recobertos com semiesteiras.

O tráfego do skidder com rodados de pneus foi a situação que mais reduziu a porosidade total e a porosidade de aeração do solo. Contudo, nota-se que a situação do tráfego do Skidder com rodados de pneus recobertos com semiesteira também apresentou reduções de porosidade, comparado à testemunha, principalmente nas camadas mais superficiais do solo. 


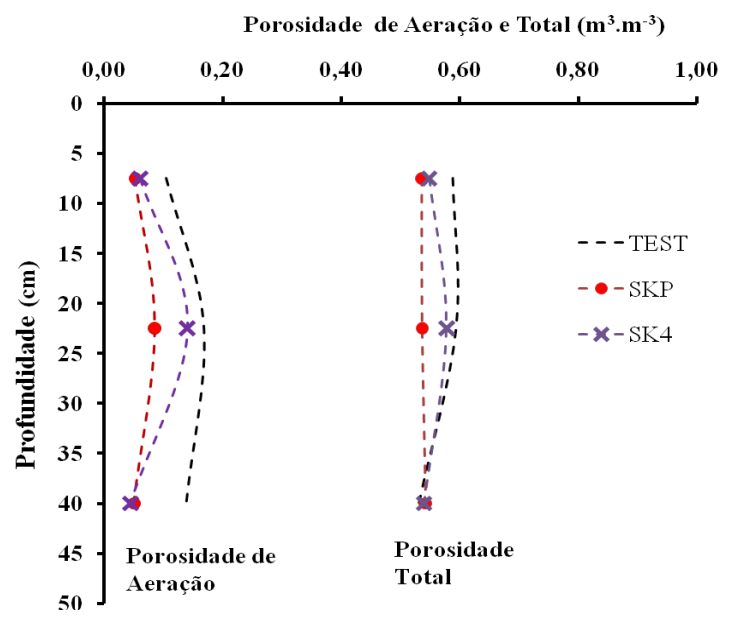

Figura 3. Porosidade de aeração e porosidade total do solo nos diferentes tratamentos.

Figure 3. Average of soil aeration and total porosity at the different treatment.

Além disso, é importante ressaltar que, tanto nas camadas mais superficiais quanto nas mais profundas, verificou-se que a porosidade de aeração foi menor que $0,10 \mathrm{~m}^{3} \cdot \mathrm{m}^{-3}$, considerado o valor crítico no qual as plantas começam a sofrer problemas de aeração (ERICKSON, 1982).

Tabela 2. Valores médios de porosidade total e de aeração nos diferentes tratamentos e profundidades. Table 2. Average values of soil total and aeration porosity at the different treatment and depth.

\begin{tabular}{|c|c|c|c|c|c|c|}
\hline \multirow{3}{*}{ Tratamento } & \multicolumn{6}{|c|}{ Profundidade $(\mathrm{cm})$} \\
\hline & 0 a 15 & 15 a 30 & 30 a 50 & 0 a 15 & 15 a 30 & 30 a 50 \\
\hline & \multicolumn{3}{|c|}{ Porosidade total $\left(\mathrm{m}^{3} \cdot \mathrm{m}^{-3}\right)$} & \multicolumn{3}{|c|}{ Porosidade de aeração $\left(\mathrm{m}^{3} \cdot \mathrm{m}^{-3}\right)$} \\
\hline TEST & 0,588 & 0,593 & 0,531 & 0,104 & 0,168 & 0,138 \\
\hline SKP & $0,536 \neq$ & $0,536 \neq$ & 0,542 & $0,052 \neq$ & $0,085 \neq$ & $0,050 \neq$ \\
\hline SK4 & $0,548 \neq$ & 0,577 & 0,539 & 0,061 & 0,140 & $0,044 \neq$ \\
\hline Valor $F$ & $13,23 * *$ & $7,04 * *$ & $0,06^{\mathrm{ns}}$ & $4,26 *$ & $5,48 * *$ & $7,65 * *$ \\
\hline
\end{tabular}

Médias seguidas de $\neq$ na coluna diferem estatisticamente da testemunha (TEST) pelo teste de Dunnett a 5 \% de significância; *: significativo a $5 \%$; **: significativo a $1 \% ;{ }^{\text {ns }}$ : não significativo.

\section{RESISTÊNCIA DO SOLO À PENETRAÇÃO}

Em relação aos valores de resistência à penetração (Figura 4 e Tabela 3), os resultados mostram que, de modo geral, houve um acréscimo na compactação do solo causado pelo tráfego do skidder na operação de extração florestal. O skidder com rodados de pneus causou o maior aumento na resistência do solo em relação à testemunha, com incrementos de 48,8; 48,2 e 47,6\% nas camadas de 0 a 15,15 a 30 e 30 a $50 \mathrm{~cm}$ de profundidade, respectivamente. Os valores obtidos estão, em média, $40 \%$ superiores à testemunha. Os resultados mostram que houve diferença significativa entre os tratamentos (SKP e SK4) e a testemunha (TEST) em todas as camadas de profundidade avaliadas.

É importante ainda ressaltar que os valores médios de resistência do solo na camada de 30 a $50 \mathrm{~cm}$ estavam com valores acima de 2,0 MPa, por ocasião do tráfego da máquina com ambos os tipos de rodados, sendo o valor considerado limite crítico ao crescimento e funcionamento radicular (WHALLEY et al., 1995).

Tal resultado pode ser devido às condições naturais do solo, ao número de passadas, ao histórico de pressões ocorridas e ao maior peso e intensidade de tráfego das máquinas, sendo comum nessas condições, segundo Reichert et al. (2007), a compactação atingir profundidades mais elevadas.

Além disso, é importante ressaltar que a semiesteira instalada nos rodados de pneus não contribuiu para o aumento da área de contato da máquina com o solo, não permitindo, consequentemente, a redução dos níveis de compactação. É possível afirmar que a semiesteira instalada nos rodados da máquina desempenha apenas a função de tracionamento, permitindo uma maior eficiência da máquina na execução 
da operação de arraste da madeira em solos úmidos, bem como o acesso em terrenos de maior declividade, onde muitas vezes a máquina com os rodados de pneus não é capaz de atuar (LOPES et al., 2007).

Tabela 3. Valores médios de resistência do solo à penetração (MPa) nos diferentes tratamentos e profundidades.

Table 3. Average values of soil penetrometer resistance (MPa) at the different treatments and depths.

\begin{tabular}{lccc}
\hline \multirow{2}{*}{ Tratamento } & \multicolumn{3}{c}{ Profundidade $(\mathbf{c m})$} \\
\cline { 2 - 4 } & $\mathbf{0 ~ a ~ 1 5}$ & $\mathbf{1 5}$ a 30 & $\mathbf{3 0}$ a 50 \\
\hline TEST & 0,51 & 1,03 & 1,05 \\
SKP & $1,01 \neq$ & $1,99 \neq$ & $2,01 \neq$ \\
SK4 & $0,71 \neq$ & $1,81 \neq$ & $2,05 \neq$ \\
Valor $F$ & $85,55^{* *}$ & $101,16^{* *}$ & $201,00^{* *}$ \\
\hline
\end{tabular}

Médias seguidas de $\neq$ na coluna diferem estatisticamente da testemunha (TEST) pelo teste de Dunnett a $5 \%$ de significância; *significativo a $5 \%$; ** significativo a $1 \% ;{ }^{\text {ns }}$ não significativo.

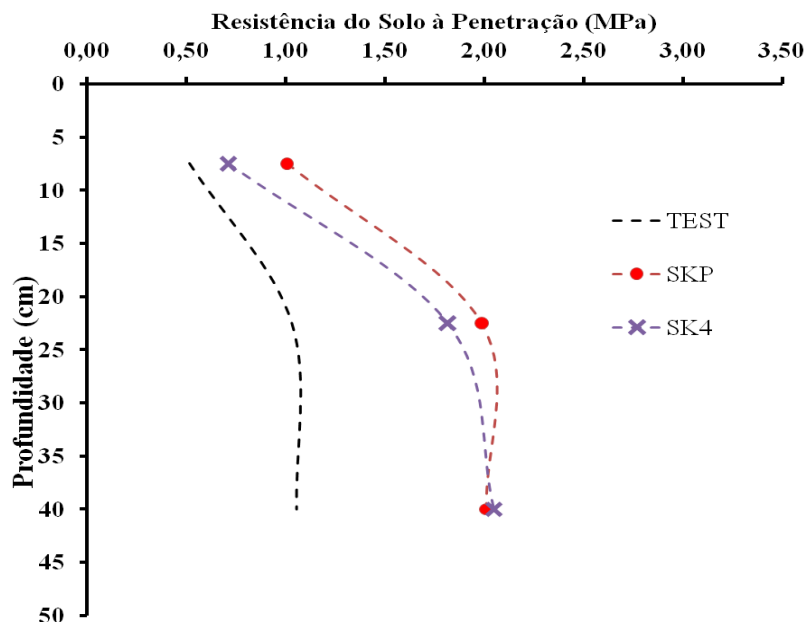

Figura 4. Resistência do solo à penetração nos diferentes tratamentos.

Figure 4. Average of soil penetrometer resistance at the differents treatments.

A figura 5 mostra a relação entre a densidade e resistência do solo à penetração e o tipo de rodado utilizado no skidder por ocasião da extração florestal. O estudo da modelagem e das relações entre as variáveis são importantes para melhor se entender a compactação do solo, permitindo avaliar alternativas para a sua minimização (DIAS JÚNIOR; PIERCE, 1996).

Como pode ser visto, a equação polinomial explicou, em média, 16,2 e 59,2\% da variabilidade da densidade do solo e da resistência do solo à penetração, respectivamente, em função do tipo de rodados nas profundidades mais superficiais do solo, sugerindo a maior susceptibilidade nessa camada de solo ao tráfego das máquinas de colheita.

\section{CONCLUSÕES}

De acordo com a análise e discussão dos resultados, as principais conclusões foram:

- De forma geral, não houve alteração significativa nas propriedades físicas do solo devido ao tráfego dos skidders com os diferentes tipos de rodado.

- A maior compactação do solo ocorreu na situação de tráfego do skidder com rodados de pneus e nas camadas maiores superficiais, porém abaixo do limite crítico de 15 a $20 \%$, que pode restringir o crescimento radicular das plantas.

- Os resultados mostraram que a instalação de semiesteiras nos rodados das máquinas não acarretou redução da compactação do solo, podendo esse acessório contribuir apenas na melhoria da capacitação de tração. 

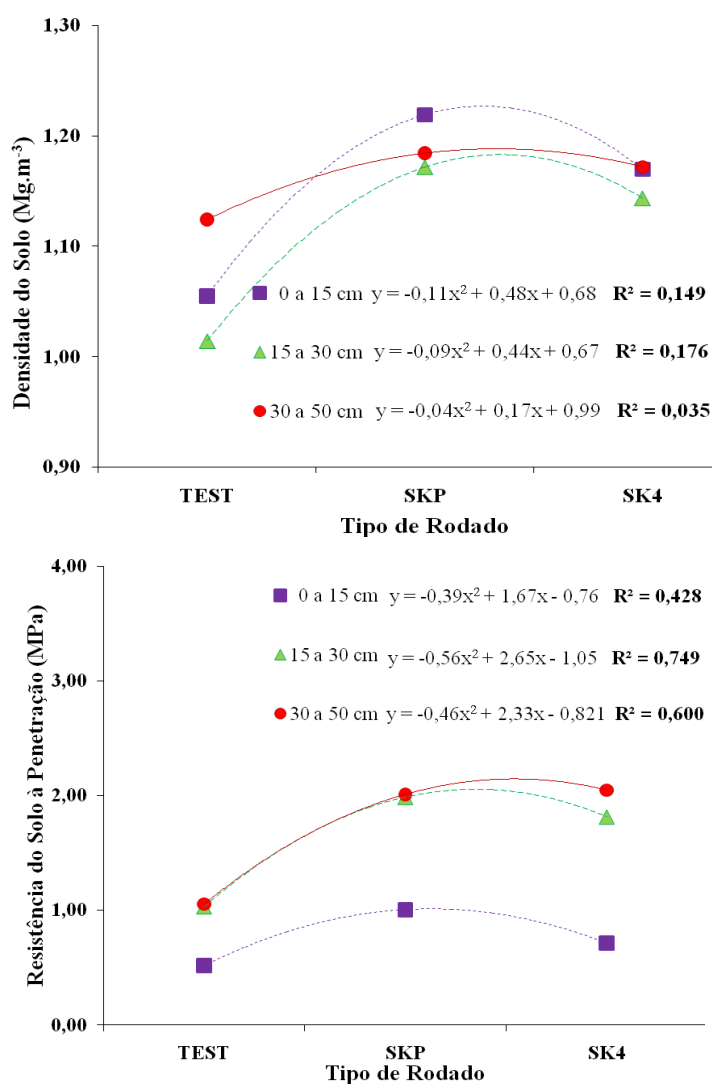

(a)

(b)

Figura 5. Relação entre a densidade do solo (a) e a resistência do solo à penetração (b) e os tipos de rodados utilizados nos skidders.

Figure 5. Relationship between the soil density (a) and soil penetrometer resistance (b) and the type of track in the skidders.

\section{AGRADECIMENTOS} área de estudo.

Ao CNPq e Fundação Araucária, pelo apoio financeiro, e à empresa florestal, pela concessão da

\section{REFERÊNCIAS}

BALASTREIRE, L. A. Máquinas agrícolas. São Paulo: Manole, 1987. 307 p.

BALLARD, T. M. Impacts of forest management on northern forest soils. Forest Ecology and Management. n. 133, p. 37 - 42, 2000.

BRAMUCCI, M.; SEIXAS, F. Determinação e quantificação de fatores de influência sobre a produtividade de "harvesters" na colheita florestal. Scientia Forestalis, Piracicaba, n. 62, p. 62 - 74, 2002.

BYGDÉN, G.; WASTERLUND, I.; ELIASSON, L. Rutting and soil disturbance minimized by planning and using bogie tracks. In: SIMPÓSIO BRASILEIRO SOBRE COLHEITA E TRANSPORTE FLORESTAL, 6. 2003, Belo Horizonte, Anais... Belo Horizonte: UFV/SIF, 2003. p. 1 - 9.

CAMARGO, O. A. Compactação do solo e desenvolvimento de plantas. Campinas: Fundação Cargil, 1983. $44 \mathrm{p}$. 
DIAS JÚNIOR, M. S. Avaliação quantitativa da sustentabilidade estrutural de um Latossolo Vermelho-Amarelo situado em áreas experimentais da Cenibra: relatório do projeto de pesquisa. Lavras: UFLA, 1999. 23 p.

EAVIS, B. W. Soil physical conditions affecting seedling root growth: 1- mechanical impedance, aeration, and moisture availability as influenced by bulk density and moisture levels in a sandy loam soil. Plant and soil, v. 36, p. 613 - 622, 1972.

ERICKSON, A. E. Tillage effects on soil aeration. In: VAN DOREN, D. M.; ALLMARAS, R. R.; LINDEN, D. R.; WHISLER, F. D. Predicting tillage effects on soil physical properties and processes. Madison: ASA, 1982. p. 91 - 104.

GEIST, J. M.; HAZARD, J. W.; SEIDEL, K. W. Assessing physical conditions of some Pacific Northwest Volcanic ash soils after forest harvest. Soil Science Society of America Journal, v. 53, p. 946 - 950, 1989.

HASSAN, A. E.; SIROIS, D. L. Transaction and rolling resistance of a dual-tired skidder on wetland. Transaction of the ASAE, v. 28, n. 5, p. 1038 - 1042, 1985.

LIMA, M. R.; SIRTOLI, A. E. Diagnóstico e recomendações de manejo do solo: aspectos teóricos e metodológicos. Curitiba: UFPR, 2006. 341 p.

LOPES, E. S. Avaliação técnica do trator florestal arrastador "skidder" com diferentes tipos de rodados na extração de madeira em povoamentos de pinus. Árvore, v. 31, n. 6, p. 1053 - 1061, 2007.

MACHADO, C. C. Planejamento e controle de custos na exploração florestal. Viçosa: UFV; Imprensa Universitária,1994. 138 p.

MAKKONEN, I. Choosing a wheeled shortwood forwarder. FERIC technical note, n. 136, p. 1 - 12, 1989.

PORTERFIELD, J. W.; CARPENTER, T. G. Soil compaction: an index of potential compaction for agricultural tires. Transactions of the Asae, St. Joseph, v. 29, n. 4, p. 917 - 922, 1986.

REICHERT, J. M.; SUZUKI, L. E. A. S.; REINERT, D. J. Compactação do solo em sistemas agropecuários e florestais: identificação, efeitos, limites críticos e mitigação. In: CERETTA, C. A.; SILVA, L. S.; REICHERT, J. M. Tópicos em ciência do solo. Viçosa: Sociedade Brasileira de Ciência do Solo, 2007. v. 5, p. 49 - 134.

SEIXAS, F. Compactação do solo devido à mecanização florestal: causas, efeitos e práticas de controle. Circular técnica IPEF, n. 163, p. 1 - 10, 1988.

SEIXAS, F. Compactação do solo devido à colheita de madeira. 75 p. Tese (Livre-docência) - Escola Superior de Agricultura "Luiz de Queiroz", Universidade de São Paulo, Piracicaba, 2000.

SEIXAS, F; MCDONALD, T. P.; STOKES, B. J.; RAPER, R. L. Effect of slash on forwarder soil compaction. In: COFE ANNUAL MEETING, 1995. Proceedings... Cashiers: COFE, 1995. p. 77 - 86.

SEIXAS, F.; SOUZA, C. R. Avaliação e efeito da compactação do solo devido à frequência de tráfego na produção de madeira de eucalipto. Árvore, v. 31, n. 6, p. 1047 - 1052, 2007.

SOANE, B. D.; OUWERKERK, C. Soil compaction problems in world agriculture. In: SOANE, B. D.; OUWERKERK, C. Soil compaction in crop production, 1994. p. 1 - 21.

SOUZA, A. P; MACHADO, C. C.; MINETTI, L. J.; JACOVINE, L. A. G. Perspectivas na área de colheita e transporte florestal. Revista da Madeira, Curitiba, 2002. p. 52 - 62.

WHALLEY, W. R.; LEEDS-HARRISON, P. B.; CLARK, L. J.; GOWING, D. J. G. Use of effective stress to predict the penetrometer resistance of unsaturated agricultural soils. Soil and Tillage Research. v. 84, p. $18-27,2005$.

WARKOTSCH, W. The impact of harvesting operation on timber quality: causes and remedies. South African Forestry Journal, Pretoria, South Africa, n. 169. 1994. 
